\title{
Hydrogen-Bond Driven Chemical Separations: Elucidating the Inter- facial Steps of Self-Assembly in Solvent Extraction
}

Azhad U. Chowdhury, Lu Lin, Benjamin Doughty*

This manuscript has been authored by UT-Battelle, LLC, under contract DE-AC05-000R22725

with the US Department of Energy (DOE). The US government retains and the publisher, by accepting the article for publication, acknowledges that the US government retains a nonexclusive, paid-up, irrevocable, worldwide license to publish or reproduce the published form of this manuscript, or allow others to do so, for US government purposes. DOE will provide public access to these results of federally sponsored research in accordance with the DOE Public Access Plan (http://energy.gov/downloads/doe-public-access-plan). 


\title{
Hydrogen-Bond Driven Chemical Separations: Elucidating the Inter- facial Steps of Self-Assembly in Solvent Extraction
}

\author{
Azhad U. Chowdhury, Lu Lin, Benjamin Doughty* \\ Chemical Sciences Division, Oak Ridge National Laboratory, Oak Ridge, Tennessee 37831, United States \\ KEYWORDS. Liquid Extraction, Micelle, Aggregation, Polymerization, Nonlinear Spectroscopy, Kinetics
}

\begin{abstract}
Chemical separations, particularly liquid extractions, are pervasive in academic and industrial laboratories, yet a mechanistic understanding of the events governing their function are obscured by interfacial phenomena that are notoriously difficult to measure. In this work, we investigate the fundamental steps of ligand self-assembly as driven by changes in the interfacial $\mathrm{H}$-bonding network using vibrational sum frequency generation. Our results show how the bulk $\mathrm{pH}$ modulates the interfacial structure of extractants at the buried oil/aqueous interface via the formation of unique H-bonding networks that order and bridge ligands to produce self-assembled aggregates. These extended H-bonded structures are key to the subsequent extraction of $\mathrm{Co}^{2+}$ from the aqueous phase in promoting micelle formation and subsequent ejection of said micelle into the oil phase. The combination of static and time resolved measurements reveals the mechanisms underlying complexities of liquid extractions at high [ $\left.\mathrm{Co}^{2+}\right]$ :[DEHPA] ratios by showing an evolution of interfacially assembled structures that are readily tuned on a chemical basis by altering the compositions of the aqueous phase. The results of this work point to new mechanistic principles to design separations through the manipulation of surface charge, electrostatic screening, and the associated $\mathrm{H}$-bonding networks that arise at the interface to facilitate organization and subsequent extraction.
\end{abstract}

\section{INTRODUCTION}

There is arguably no sub-discipline more foundational to the study of chemistry than that of chemical separations. ${ }^{1}$ The ability to isolate chemical species from one another is routine in synthetic chemistry laboratories and is integral to industrial processing and mining operations targeting precious or critical elements. ${ }^{2-3}$ While there is an obvious ability from the aforementioned examples that one can perform a given separation, many approaches are optimized to work in very specific chemical scenarios and/or are incredibly energy intensive. Changes in these conditions or compositions can severely limit the selectivity of the separation. This has implications on the associated energy consumption and environmental impact for a given process, and thus on the overall cost and feasibility of using one scheme (or chemical species) vs. another. In fact, roughly $10-15 \%$ of the world's energy use is directed to chemical separations. ${ }^{4} \mathrm{Av}$ enues to improve efficiency and selectivity could dramatically reduce processing costs and the associated environmental impact. These pragmatic reasons to improve chemical separations; however, are limited by the basic problem in understanding how extractions take place on the molecular level.

The limited mechanistic information regarding separations originates from the fact that the essential chemistry takes place at an interface. ${ }^{1}$ For instance, crystallization, ${ }^{5-6}$ membrane separations, ${ }^{7-9}$ or liquid extractions ${ }^{10-13}$ necessarily leverage interfacial molecular interactions that ultimately dictate the fidelity of the separation. Of those mentioned, liquid extraction techniques are amongst the most used, efficient and selective approaches ${ }^{13-15}$ for the isolation of target species from complex chemical mixtures. As such, methods based on liquid extraction have found uses in a range of fields and industrial applications including rareearth element recovery ${ }^{16-18}$ and nuclear waste cleanup/remediation. ${ }^{19-21}$ Despite the widespread implementation of these methods the mechanisms underlying their success are surprisingly poorly understood despite decades of research. ${ }^{13}$ This lack of mechanistic understanding limits the development of new extraction schemes designed to isolate species (or sets of species) from arbitrary mixtures and arises from anomalous chemical phenomena and structural motifs that naturally arise at the interface between the two liquid phases. Understanding the emergent structures, where charged/polar species in the aqueous phase must somehow transform into a neutral hydrophobic moiety at a chemically asymmetric interface, represents the missing insight into what drives selective chemical extractions. ${ }^{1}$

While mechanistically important, actually probing these active species at molecularly thin interfaces is notoriously challenging owning to the large number of species in the neighboring bulk phases that dominate traditional measurement techniques. Adding to this complexity is the intrinsically dynamic nature of chemical separations and associated supramolecular chemistry, as sketched in Fig. 1, that involves self-assembly, changes in solvation/coordination, large-scale reorganizational processes, and mass transport that must work in concert for an extraction to take place. ${ }^{22-}$ 25 These dynamic processes have timescales spanning femtoseconds to minutes, suggesting that studying the extracted products using static models of chemical binding and thermodynamics is not enough to understand how a separation works or how to rationally design new extractions. To truly understand how liquid extractions function, one must study the separation processes in situ and at the places where they occur: the buried liquid/liquid (L/L) interface. 


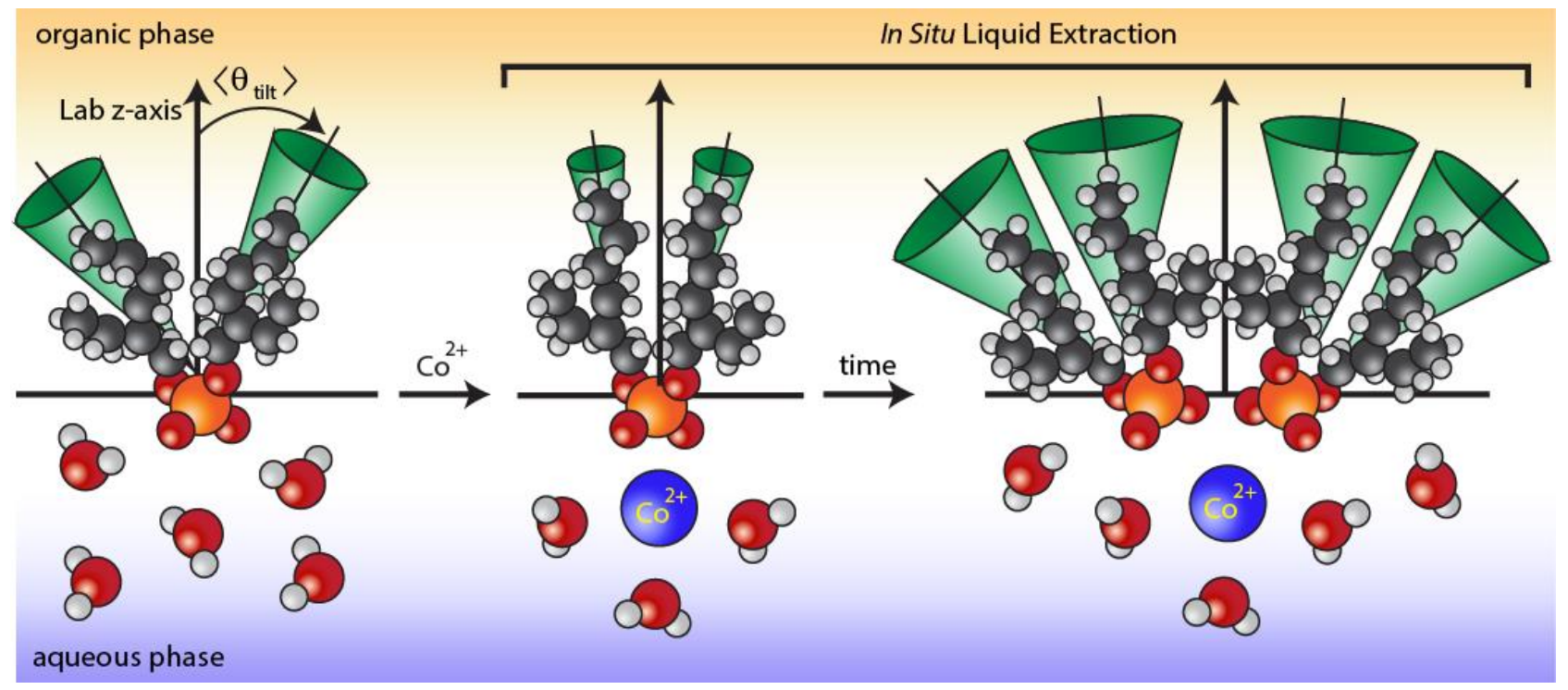

Figure 2: The interface between an organic and aqueous phase decorated with extractants can be characterized by $\mathrm{H}$-bonding networks, orientation (denoted as the tilt angle of methyl groups, $\left\langle\theta_{\text {tilt }}>\right.$ ) and the ordering of the hydrocarbon tails (denoted as green shaded cones). These structural and chemical signatures evolve in time as complexes, dimers and higher order aggregates are formed. Probing changes in the structural/chemical signatures provides key insight into the events taking place at the interface that are central to liquid extractions.

To address these challenges, we make use of the surface specific nonlinear spectroscopy vibrational sum-frequency generation (SFG) to take molecular snapshots of the interfacial chemistry and organization during extraction at the $\mathrm{L} / \mathrm{L}$ interface. While substantial work has been made in understanding chemistry at a range of chemical interfaces, the study of L/L interfaces has received remarkably little attention. Of the reports in the literature, the seminal work of Richmond ${ }^{26-29}$ and Roke ${ }^{30-32}$ using SFG based methods to probe buried L/L interfaces has revealed novel H-bonding networks, chemical partitioning and peculiar interfacial structures that emerge at model and increasingly complex organic-aqueous interfaces. Our recent work expanded on these key discoveries by probing the evolution of a 'neat' oilaqueous interface as it transformed into an amphiphilic oligomer decorated L/L interface - tunability of the oligomer structures in the oil phase was achieved via interactions with anions in the aqueous phase. ${ }^{33}$ Complimentary methods probing dynamic L/L interfaces, such as X-ray ${ }^{34-37}$ and neutron scattering, ${ }^{36-38}$ have provided key insight into the concentration profile of elements across the phase boundary showing a complex interplay between aqueous and oil phase structures. Computational methods have also begun to connect chemical phenomena ${ }^{39-42}$ with larger scale structural changes and fluctuations $\mathrm{s}^{43-45}$ that are likely integral to the mechanisms of chemical separations as mediated by interfaces.

The work presented in this report builds on these experiments and simulations by probing the interfacial chemistry and structures of a model extractant, di-(2-ethylhexyl) phosphoric acid (DEHPA) at 'neat' interfaces and in the presence of divalent cobalt ions, as sketched in Fig. 2. The demand for cobalt is consistently rising due to its key role in a wide range of modern materials and devices; however, the production of this element is dominated by only a few countries. ${ }^{46-47}$ A secure and ethically sourced supply of cobalt is therefore essential to its continued use in technology and in securing industrial supply chains. ${ }^{46-47}$ Extraction of $\mathrm{Co}^{2+}$ ions from companion species such as $\mathrm{Ni}^{2+}, \mathrm{Cu}^{2+}$ and $\mathrm{Mn}^{2+}$ in both raw and in recycling contexts ${ }^{48}$ emphasize the need to develop selective separations to differentiate between chemically similar species that coexist in diverse source materials. The selective extraction of such divalent transition metal cations can be accomplished using DEHPA by manipulating the bulk aqueous phase $\mathrm{pH}{ }^{49-50}$ It is recognized that the $\mathrm{p} K_{a}$ of the ligand plays some role in the selectivity of the extraction at a given $\mathrm{pH} ; 49-50$ however, if the protonation state of the ligand were all that mattered, naively speaking, structurally similar ligands with similar $\mathrm{p} K K_{a}^{\prime} \mathrm{s}$ would work the same. This is not observed. ${ }^{49-50}$ Instead there is a complex relationship between the nature of the polar/charged headgroup, the chemical makeup of the tail (how bulky, electron withdrawing, etc...), the ionic strength and specific ion effects in the aqueous phase, and the polarity/structure of the diluent. ${ }^{49-50}$ We show that probing the changes in the structural and chemical signatures of the interfacial species during the extraction of $\mathrm{Co}^{2+}$ provides key insight into the mechanisms of liquid extraction that have eluded direct measurement for decades. Specifically, we illustrate how the bulk pH imparts structure to the interfacial

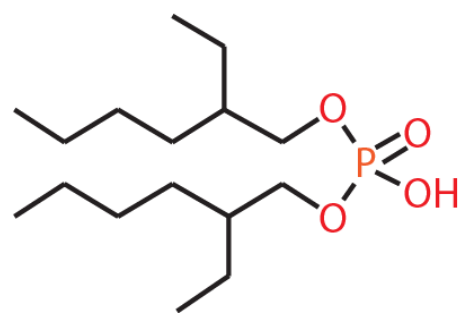

Figure 1: Chemical structure of di-(2-ethylhexyl) phosphoric acid (DEHPA). Color schemes for elements match those in other figures. 


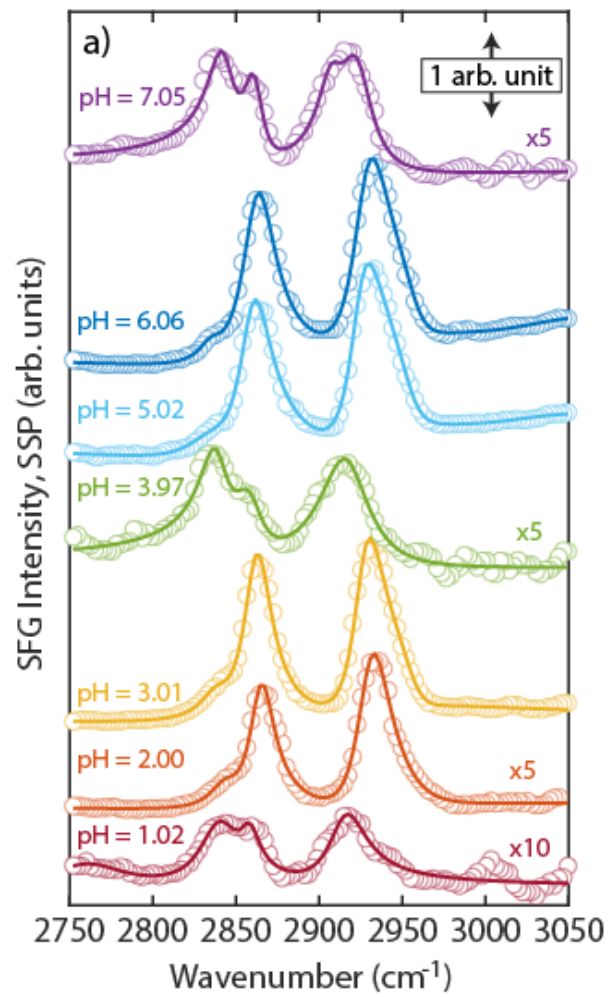

layer through unique $\mathrm{H}$-bonding networks that bridge ligands to form self-assembled interfacial aggregates. These $\mathrm{H}$ bonding networks are key to the subsequent extraction of $\mathrm{Co}^{2+}$ from the oil phase in promoting micelle formation and subsequent ejection of said micelle into the oil phase. Our results point to new design principles that could enable novel energy efficient separations through the manipulation of surface charge, electrostatic screening, and the associated H-bonding networks that arise and facilitate organization and overall selectivity.

\section{RESULTS AND DISCUSSION}

\section{Probing 'neat' DEHPA Decorated Oil/Aqueous Interfaces}

In these experiments, DEHPA was dissolved into an $\mathrm{n}$ hexadecane oil phase and placed in contact with an aqueous phase composed of $200 \mathrm{mM} \mathrm{NaCl}$ that was $\mathrm{pH}$ adjusted using concentrated $\mathrm{HCl}$ or $\mathrm{NaOH}$. Throughout this work, we define the L/L interface as the molecularly thin layer separating two macroscopic liquid phases. This contrasts with studies of lipid, ligand, or surfactant monolayers adsorbed at the air/aqueous or solid/aqueous interface. Monolayer interfaces are fundamentally different than a buried L/L interface where two macroscopic and dynamic bulk liquid phases are present, which allows for mass transport and organization across the interface exactly as it would during a liquid extraction. Details surrounding the SFG measurements and data analysis can be found the Materials and Methods section and the Supporting Information.

To understand the role of bulk $\mathrm{pH}$ on the interfacial structure and chemistry discussed above, we measured SFG spectra using SSP and PPP polarization combinations as shown in Fig. 3a and 3b. The SSP polarization combination probes predominantly symmetric stretching modes that are
Figure 3: SFG spectra in the SSP (a) and PPP (b) polarization combinations at different aqueous phase $\mathrm{pHs}$. The data (points) are fit (solid lines) to Equations 2 and 3. A summary of fit parameters is supplied in the Supporting Information. Spectra are offset for clarity and scaled (as noted) for ease of comparison. oriented out the interfacial plane, whereas the PPP spectrum preferentially measured asymmetric stretches and orientational components that lay more parallel to the interface. ${ }^{51}$ These spectra clearly show a strong dependence of the SFG intensity and associated spectral features on the bulk aqueous phase $\mathrm{pH}$. Based on previous reports, we can assign the peaks in the spectrum; key features include bands observed near $2838 \mathrm{~cm}^{-1}$ and $2861 \mathrm{~cm}^{-1}$, which correspond to methylene $\left(-\mathrm{CH}_{2}\right)$ and methyl $\left(-\mathrm{CH}_{3}\right)$ symmetric stretches (-sS) of DEHPA, respectively. ${ }^{51-52}$ The feature near $2926 \mathrm{~cm}^{-1}$ is assigned to a Fermi resonance (FR) with contributions from weak unresolved asymmetric stretching modes. The broad shoulder at higher frequencies $(\omega>3000$ $\mathrm{cm}^{-1}$ ) is due to interfacial water and associated $-\mathrm{OH}$ stretches. The strong feature near $2950 \mathrm{~cm}^{-1}$ in the PPP spectrum corresponds to the methyl asymmetric stretch (as) of DEHPA. ${ }^{53}$ Notably, these band positions differ from the neat oil/water interface reported previously. ${ }^{30,33}$

To quantify the different spectral responses at each $\mathrm{pH}$, we plot the normalized SFG amplitudes of the methyl symmetric stretches and the integrated SFG field from water vs. pH in Fig. 4a. The SFG amplitude/field describes the interfacial population convolved with orientational effects. ${ }^{51}$ These results show that at $\mathrm{pHs} \sim 1-2$ the SFG signals are weak but precipitously increase at $\mathrm{pH} \sim 2.5-3$, which is accompanied by an obvious change in relative band intensities throughout each spectrum (see Fig. 3). The SFG signal then drops at $\mathrm{pH} \sim 4$, increases again until the $\mathrm{pH}$ is about 6.5 after which the signal again drops off. The relative differences between the methyl vibrations and water signals (Fig. 4a) indicates that the amount of ordered water, and therefore the associated interfacial H-bonding network, is different in the $\mathrm{pH}$ window of $\sim 2.5-3.5$ vs. that of $\mathrm{pH} \sim 4.5$ -6.0 . 

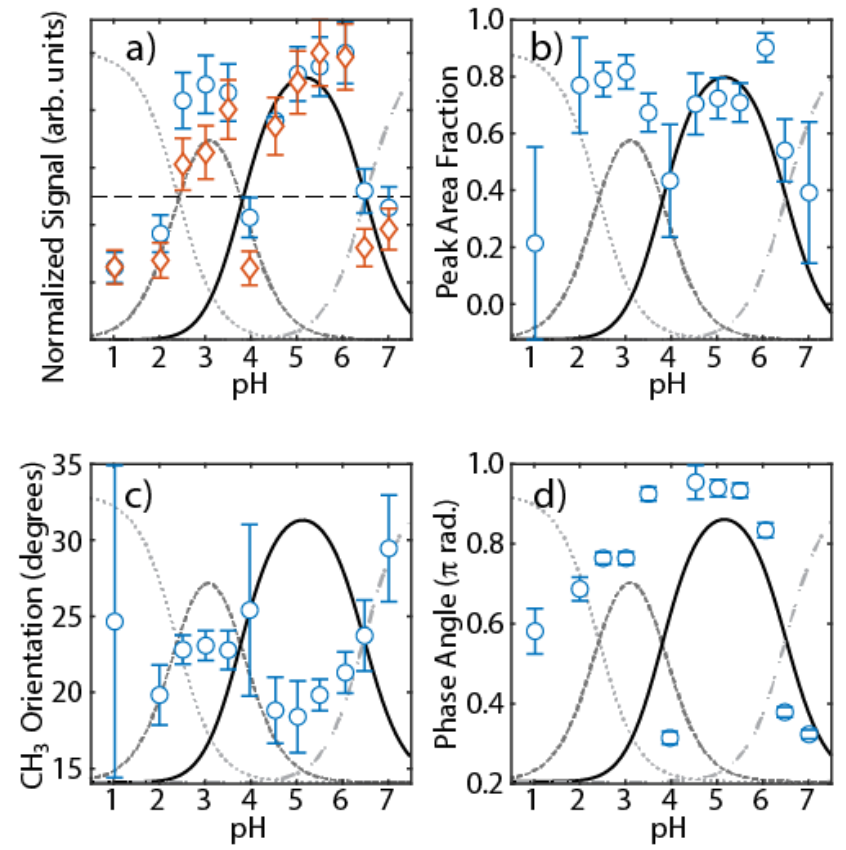

Figure 4: Normalized integrated peak areas/amplitudes are plotted in a) for water (orange diamonds) and - $\mathrm{CH}_{3}$ symmetric stretches (blue circles), respectively. The peak area fraction (PAF) is plotted in b) vs. pH. Data in c) shows the average orientational angle the methyl groups take with respect to the surface normal as a function of $\mathrm{pH}$. Finally, the extracted phase angle is plotted vs. $\mathrm{pH}$ in d). Overlaid on all the plots are the populations of different chemical species observed with static measurements and solved for in the bulk. The light grey dotted line is the protonated ligand, LH, the dark grey dashed line is the corresponding conjugate base, $\mathrm{L}$; the solid black line is an aggregate species, $\mathrm{A}$, and the dot-dashed line is an extended aggregate, $\mathrm{E}$, as described in the text.

To remove the contribution from a potentially varying interfacial population we calculated the peak area fraction (PAF), which is an ordering parameter describing the packing efficiency of the alkyl tails at the interface, ${ }^{54}$ as shown in Fig. 4b. For a well-ordered interfacial layer, signals corresponding to methylene stretches should be small due to in plane rotational isotropy, whereas poorly organized or loosely packed interfaces can have appreciable methylene signals due to gauche conformers in the hydrocarbon tail that break the interfacial symmetry. ${ }^{54-57}$ Larger values for the PAF are indicative of fewer methylene stretches and therefore fewer gauche conformers in the interfacial layer. Since gauche conformers are less favorable in tightly packed monolayers, a larger PAF represents a higher quality surface monolayer and tighter packing of the ligands. Notably, a similar trend is seen in the PAF vs. pH as was seen with population: there are clear windows of ordering where the ligands are well organized, but at very high or low $\mathrm{pH}$, the surface becomes disordered. $\mathrm{pH} 4$ is anomalous again in that it results in a poorly ordered interface.

To identify orientational changes that result from different pHs we plot the average methyl tilt angle in Fig. 4c vs. $\mathrm{pH}$ using previously reported methods and physical constants. ${ }^{33,58}$ Notably, the orientation of the terminal methyl groups near $\mathrm{pH} 3$ takes on a consistent average tilt angle of $23 \pm 1^{\circ}$ with respect to the surface normal whereas a more upright orientation, $18 \pm 2^{\circ}$, was found at $\mathrm{pH} 5$ and varies with $\mathrm{pH}$. The difference in orientational angles is indicative of a structural change in the interface at higher $\mathrm{pHs}$ that will be discussed more below.

Finally, we plot in Fig. 4d the nonresonant phase angle, $\phi$, extracted from the fit data vs. $\mathrm{pH}$. It has been shown that the nonresonant background can contain contributions from bulk water molecules that are polarized in the static field setup by the charged interfacial species. ${ }^{59-60}$ This contribution mixes into the resonant contributions via $\phi$ (see Experimental section). The Debye length is related to $\phi$ and thus describes the interfacial static electric fields that arise from the charged ligands. ${ }^{59}$ The data in Fig. $4 \mathrm{~d}$ shows that on increasing the $\mathrm{pH}$, the phase angle increases and indicates that $\mathrm{pH}$-dependent interfacial electrostatics impact the ordering of water at the interface even at the somewhat large ionic strengths used in this work.

To explain these changes in apparent surface chemistry and unify the above-mentioned observations, we have constructed a simple chemical model involving the presence of four species at the $\mathrm{L} / \mathrm{L}$ interface. We start by noting that at low $\mathrm{pH}, \mathrm{DEHPA}$ will be in its protonated state given the $p K_{a}$ of 2.4 as obtained via surface tensions measurements (Fig. S2 in supporting information) and in agreement with other work. ${ }^{49}$ We also measured a $\mathrm{pH}$ dependence in the formation of an aggregate species (i.e., nanodroplets $/ \mathrm{mi}$ celles), $A$, in the aqueous phase (Fig. $\mathrm{S} 3$ in supporting information) with a $\mathrm{p} K_{A}=3.8$ for aggregation. The scattering intensity and size of these aggregated structures, estimated from UV-Vis spectroscopy and dynamic light scattering, ${ }^{61}$ changes near the bulk $\mathrm{pH} \sim p K_{E} \sim 6.25$, into what we qualitatively term extended aggregates, $E$, with larger average sizes. ${ }^{61}$ A similar result is often observed at high metal loading and pHs where emulsions can form due to the formation of large-scale aggregates and clusters. ${ }^{11-12,61-62}$ Our simple model and results are consistent with the formation of nanostructures containing extracted $\mathrm{Na}^{+}$and water spanning a continuum of chemical compositions, as discussed in detail elsewhere.11-12, 62 Using these constants we can numerically evaluate the following reaction to estimate the concentrations of the different species as a function of $\mathrm{pH}$ :

$$
L H \stackrel{K_{a}}{\leftrightarrow} L^{-}+H^{+} \stackrel{K_{A}}{\leftrightarrow} A \stackrel{K_{E}}{\leftrightarrow} E
$$

here, $L H$ is the protonated DEHPA ligand, $L$ - is the conjugate base, $A$ is an interfacial aggregate that will be discussed further below, and $E$ is an extended aggregate ${ }^{61}$ found at high loading/pHs that are presumed to relate to the formation of interfacial micelles or other centrosymmetric species, as will be discussed in more detail below. The pH dependent concentrations of these various species are plotted Fig. $4 \mathrm{a}-$ $4 \mathrm{~d}$ as grey lines as detailed in the caption. Other equilibria can also be included, such as formation of sodiated and partially protonated dimers/aggregates but only has the effect of distributing relative concentrations of $L H, L, A$ and $E$ to related species that are already presumed to be involved in the equilibria. ${ }^{11,63}$ As such, to keep the model to a minimum, we only consider the four species described above. 
Remarkably this simple model parallels the measured SFG populations and the associated $\mathrm{pH}$ dependences as shown in Fig. 4a - 4d. The pH dependence of SFG derived observables can thus be explained via the following mechanism: as DEHPA deprotonates near $\mathrm{pH} 2.4$, the signal from DEHPA ligand tails increases, corresponding to the adsorption of deprotonated ligands to the interface. The negatively charged headgroups of the amphiphilic ligands will polarize bulk water molecules to generate enhanced SFG signals in the water stretching region. The fact that there are differences in the water signals at lower $\mathrm{pH}$ vs. higher $\mathrm{pHs}$ suggests that the effect of $\mathrm{pH}$ is not just an electrostatic effect that arises from neutralization/charge screening. This is because above the $\mathrm{p} K_{a}$ a majority of the ligands will be deprotonated and saturate the interfacial layer. ${ }^{64}$ This means that changes in the water SFG signals above the $\mathrm{p} K_{a}$ arise from protons at the interface participating in and altering the $\mathrm{H}$ bonding networks near the surface. ${ }^{65-68}$ Changes in the Hbonding network correlates with changes in the ligand ordering and interfacial structures as evidenced by the PAF and orientational angles measured via SFG. A similar effect was observed in our previous work studying ionic oligomers, where the structure of the hydrophobic tails could be controlled via charge screening and $\mathrm{H}$-bonding in the aqueous phase. ${ }^{33}$ Here we show that changing the $\mathrm{pH}$ influences the DEHPA tail conformational freedom even though the tails are localized in the oil phase and do not directly interact with the aqueous phase. This tunability is accomplished by manipulation of the $\mathrm{H}$-bonding at the interface, and as will be verified below, through direct interactions of water with the charged amphiphilic head groups.

Near $\mathrm{pH} 4$, where the SFG signals drop, we find that there is a cross over in our model between the deprotonated monomer species and the formation of an aggregate species, $A$. This crossover is presumed to be linked to micelle formation that arises from $\mathrm{H}$-bonding in the aqueous phase to form aggregates at the $\mathrm{L} / \mathrm{L}$ interface. This is supported by additional SFG measurements shown in Fig. 5 that probe characteristic changes in the water spectra in the $\sim 3200$ $\mathrm{cm}^{-1}$ region. Here we find that the central frequency of the $\mathrm{OH}$ stretch observed at lower $\mathrm{pHs}$ is blue shifted relative to that observed at $\mathrm{pH} \sim 5-\sim 6.5$. Based on previous work, tightly bound water interacts with charged phosphate

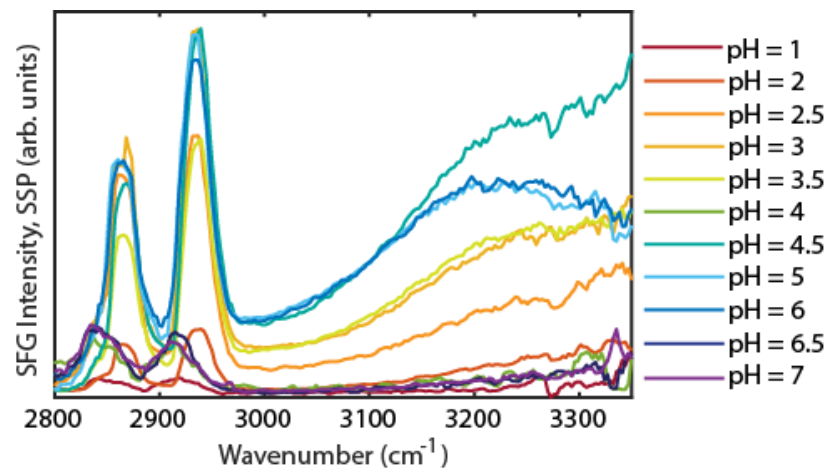

Figure 5: Measurements in the $-\mathrm{OH}$ stretching region showing the change in DEHPA ligand ordering and associated $\mathrm{H}$-bonding network at different pHs. At pHs between 5 and 6 a notable redshift of the -OH stretches is observed and suggests interactions of water with the charged phosphate groups on DEHPA to form water bridged aggregates at the interface.

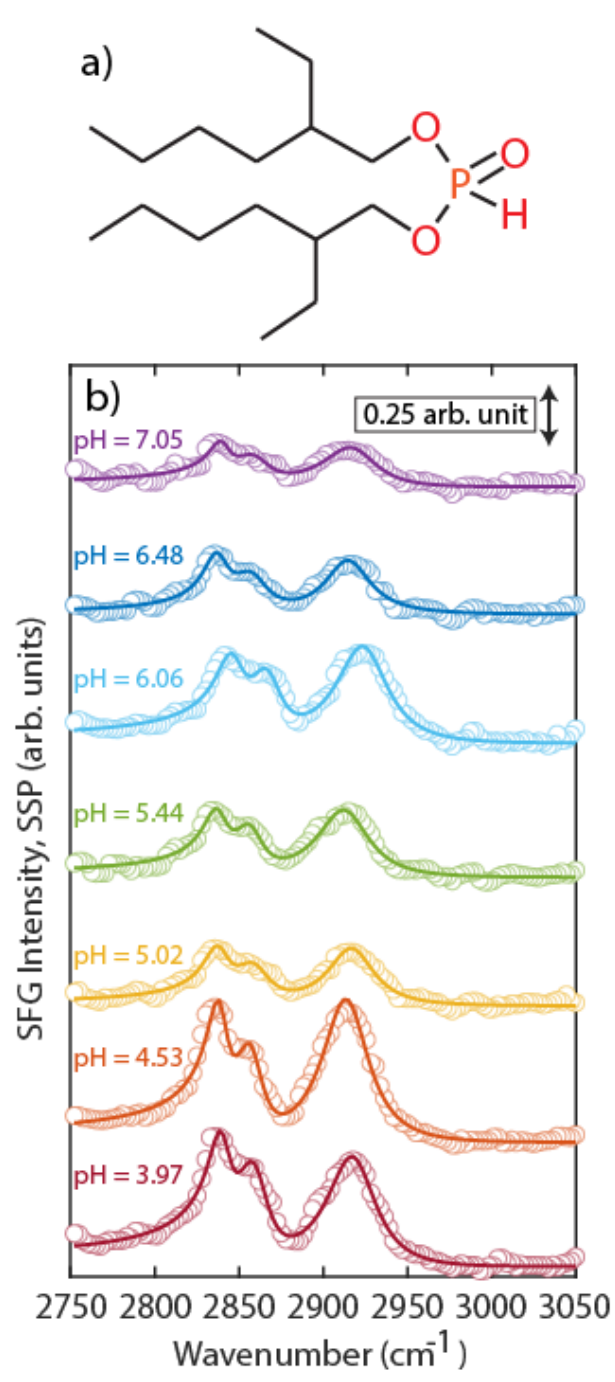

Figure 6: The structure of di(2-ethylhexyl) phosphite, a control molecule, is shown in a). Corresponding SFG spectra of this species at the $\mathrm{L} / \mathrm{L}$ interface at aqueous phase $\mathrm{pHs}$ is shown in b) in the SSP polarization combination.

groups in the backbone of DNA to yield a characteristic peak precisely at the same region we see in our data. ${ }^{71}$ This suggests, along with the intensity changes discussed earlier, that the water in the aqueous phase directly interacts with the charged phosphate groups of the ligands to form a tightly bound $\mathrm{H}$-bonding network between ligands at the interface.

To test this hypothesis, control measurements were made on a structurally similar di(2-ethylhexyl) phosphite ligand (structure in Fig. 6a) that lacks an acidic proton. The corresponding SFG spectra at the hexadecane/aqueous interface are given in Fig. $6 \mathrm{~b}$ show that the phosphite species never form an organized monolayer regardless of the bulk $\mathrm{pH}$. Given the only difference between ligands is the presence of the - $\mathrm{OH}$ group, and thus an ability to form extended $\mathrm{H}$-bonding networks, we can conclude that $\mathrm{H}$-bonding serves to organize the organic species in the oil phase via interactions in the aqueous phase. This also means that interactions between the phosphate headgroup and water are intrinsic to the self-assembly of these interfacial aggregates. This physical picture is sketched in Fig. 7 where at pHs $>4.5$, water acts as interfacial glue to link together ligands to form 


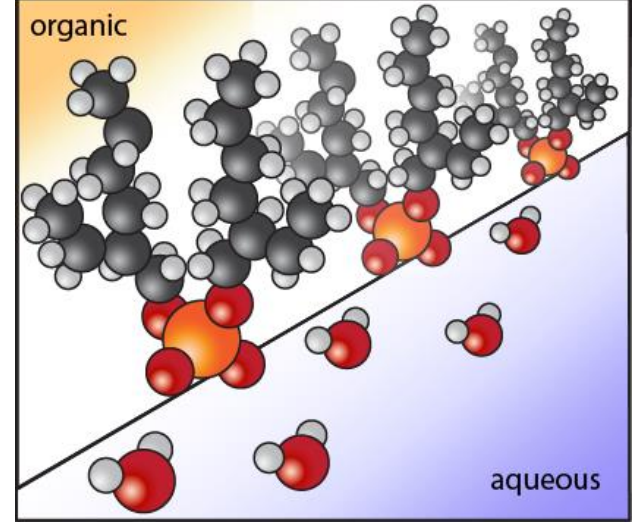

Figure 7: Proposed regimes of DEHPA ordering as driven by $\mathrm{pH}$ and the associated $\mathrm{H}$-bonding network at the buried $\mathrm{L} / \mathrm{L}$ interface. The formation of a $\mathrm{H}$-bonding mediated aggregate is found over a $\mathrm{pH}$ range of $\sim 4.5<\mathrm{pH}<6.5$ as evidenced by SFG spectra and control measurements.

an aggregated structure even at a 'neat' interface. The differences in interfacial organization of the hydrocarbon tails arises from $\mathrm{H}$-bonding in the aqueous phase such that DEHPA is arranged into linear aggregates via water bridging in the aqueous phase.

The SFG measured interfacial aggregates are thought to be precursors to micellar structures that are the vehicle for the transport of ions into the organic phase. ${ }^{10}$ Capillary waves, which arise from instantaneous fluctuations of the interfacial molecular populations at the L/L phase boundary, produce a roughened surface with regions of varying curvature.43-45 It was hypothesized from X-ray scattering measurements that the extraction of divalent cations is accomplished via the budding of a micelle at the interface. ${ }^{35}$ Analogous work, using a combination of theory and experiment have shown evidence of the presence of water 'fingers' ${ }^{39}$ channels, $^{72}$ 'ridges', ${ }^{73}$ and micellar precursors ${ }^{74}$ at a range of interfaces. The SFG measurements presented here support this physical picture by demonstrating the existence of molecular aggregates at the neat interface. An aggregate bridged by H-bonded water molecules that is subject to a surface capillary wave can respond to the changing surface curvature to form a micelle or other extractable aggregate via these mechanisms. Indeed, small angle neutron scattering measurements of these and similar systems show the presence of 'thin rod like structures' and other aggregates in bulk solutions that is consistent with the formation of interfacial aggregates. ${ }^{25,} 75$ This physical picture is also supported by the PAF data in Fig. 4b that showed a slightly better ordered interface at lower pHs, whereas at higher pHs, where curvature would be introduced via micelle formation, the area for ligands to move would be larger and should (and does) yield a lower PAF. Similarly, the change in average $\mathrm{CH}_{3}$ orientation, as alluded to earlier, suggests that the surface morphology is different and is in line with the assembly of a complex aggregate structure at the interface. Finally, we note that the phase angle of the nonresonant component increases and plateaus over the $\mathrm{pH}$ range covered. At $\mathrm{pH} \sim 4.5$ one reaches a maximum phase and corresponds to a ligand saturated surface, as expected based on the $\mathrm{p} K_{a}$ of DEHPA. We should note that crossover observed at $\mathrm{pH} 4$ in the SFG response corresponds to the half-maxi- mum of the extraction efficiency curve provided in the supporting information (Fig. S4). The combination of these results suggests that the pathways available for extraction at low pHs differ from those available at higher pHs, as will be discussed more below. Future studies are needed using methods such as molecular dynamics and small angle Xray/neutron scattering measurements to understand in more detail what is happening at $\mathrm{pH} 4$ from a structural and chemical perspective.

\section{Probing Interfacial Aggregation and Extraction with SFG}

To understand how the neat interface transforms during an extraction and what new structural/chemical motifs arise to facilitate extraction, we have performed time resolved SFG measurements in the presence of $\mathrm{Co}^{2+}$. These experiments were made by depositing the DEHPA (500 mM) containing hexadecane oil phase at a fixed concentration onto the aqueous phase containing $0.2 \mathrm{M} \mathrm{NaCl}$ and dilute, but variable, concentrations of $\mathrm{CoCl}_{2}$. The ratio $\left[\mathrm{Co}^{2+}\right]:[\mathrm{DEHPA}]$ relates to the loading regime for the extraction; loadings greater than 0.1 are considered high and result in complex extraction products and aggregates. While this is a 'non-ideal' regime to work in in terms of a well-defined chemical species being extracted, ${ }^{50}$ high loading liquid extractions are industrially desirable to minimize materials and waste that have to be subsequently treated to make for a 'greener' separation. ${ }^{11}$ The interfacial kinetics were probed by monitoring the SFG signals vs. time immediately after contacting the two phases without mixing. As such, the measured timescales do not represent intrinsic rate constants, but are diffusion limited, and serve to describe the formation/presence of interfacial species/intermediates.

The kinetic SFG data presented in Fig. 8 shows the impact of $\mathrm{pH}$ and $\left[\mathrm{Co}^{2+}\right]$ :[DEHPA] ratio on the interfacial chemistry and structure. Experiments carried out at pH 2 (data not shown) found no evidence of ordering regardless of $\left[\mathrm{Co}^{2+}\right]:[\mathrm{DEHPA}]$ and are not considered further. Notably, we find in all cases, including $\mathrm{pH} 4$, the presence of $\mathrm{Co}^{2+}$ induces ordering to the interface as evidenced by the presence of strong DEHPA ligand vibrations, weak methylene signatures, and spectroscopically distinct - $\mathrm{OH}$ signals. The variability in peak ratios for DEHPA: $\mathrm{H}_{2} \mathrm{O}$ SFG signals observed in all cases represents chemically distinct interfacial aggregates that are formed based on the bulk $\mathrm{pH}$ and $\mathrm{Co}^{2+}$ concentration. This is supported by SANS measurements probing extracted aggregates in the bulk oil phase at high $\mathrm{Co}^{2+}$ concentrations that show different structures depending on the chemical makeup of the bulk phases. ${ }^{75}$ Notably, at $\mathrm{pH} 4$ the presence of $\mathrm{Co}^{2+}$ induces ligand ordering, as evidenced by strong DEHPA tail and water vibrations, in stark contrast to the neat interface (also see Fig. S5 in the supporting information for control measurements) The presence of ordered ligands at $\mathrm{pH} 4$ suggests that $\mathrm{Co}^{2+}$ plays a similar role to water in bridging the interfacial ligands to form extended aggregate structures but only if the interface is composed of mostly deprotonated species (i.e., no ordering was found below the $\mathrm{p} K_{a}$ for DEHPA at $\mathrm{pH}$ 2). Mechanistically, this means that at high $\mathrm{Co}^{2+}$ concentrations, extractable aggregates form at the interface and are the species observed in the kinetic data in Fig. 8 at early times. These aggregates are likely the intermediates that determine selectivity and are 


\section{$\mathrm{Co}^{2+}:$ DEHPA}

$(1: 8)$
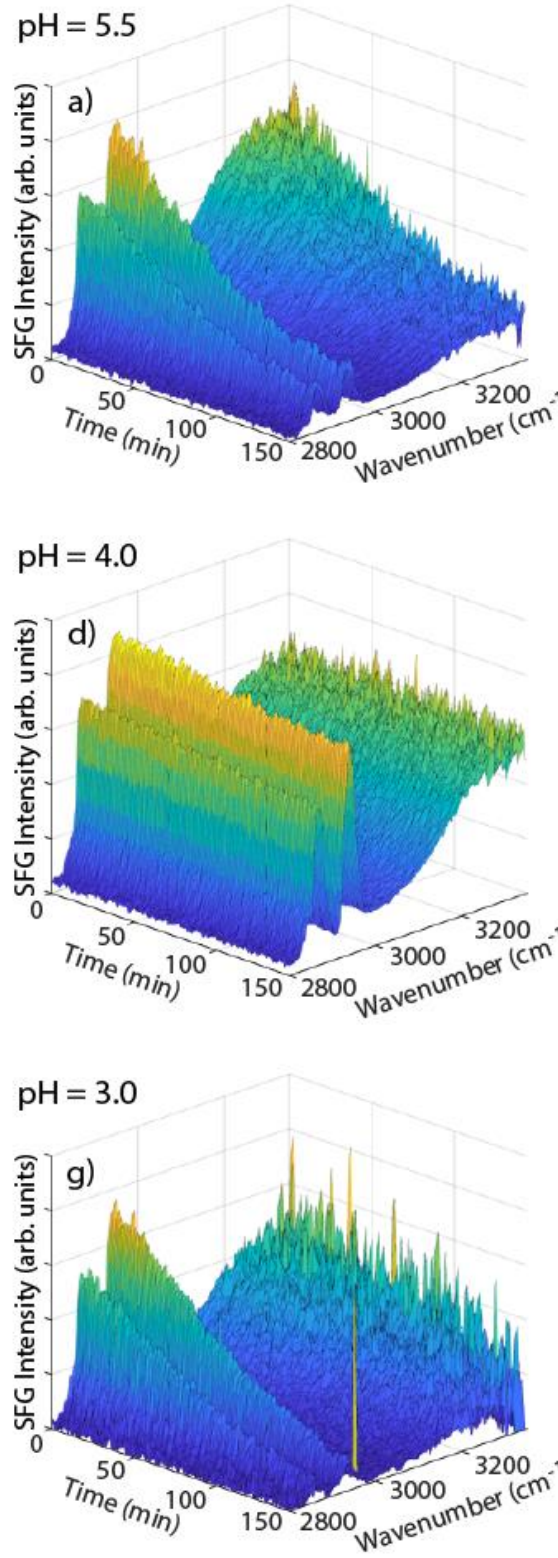

$\mathrm{Co}^{2+}:$ DEHPA

$(1: 4)$
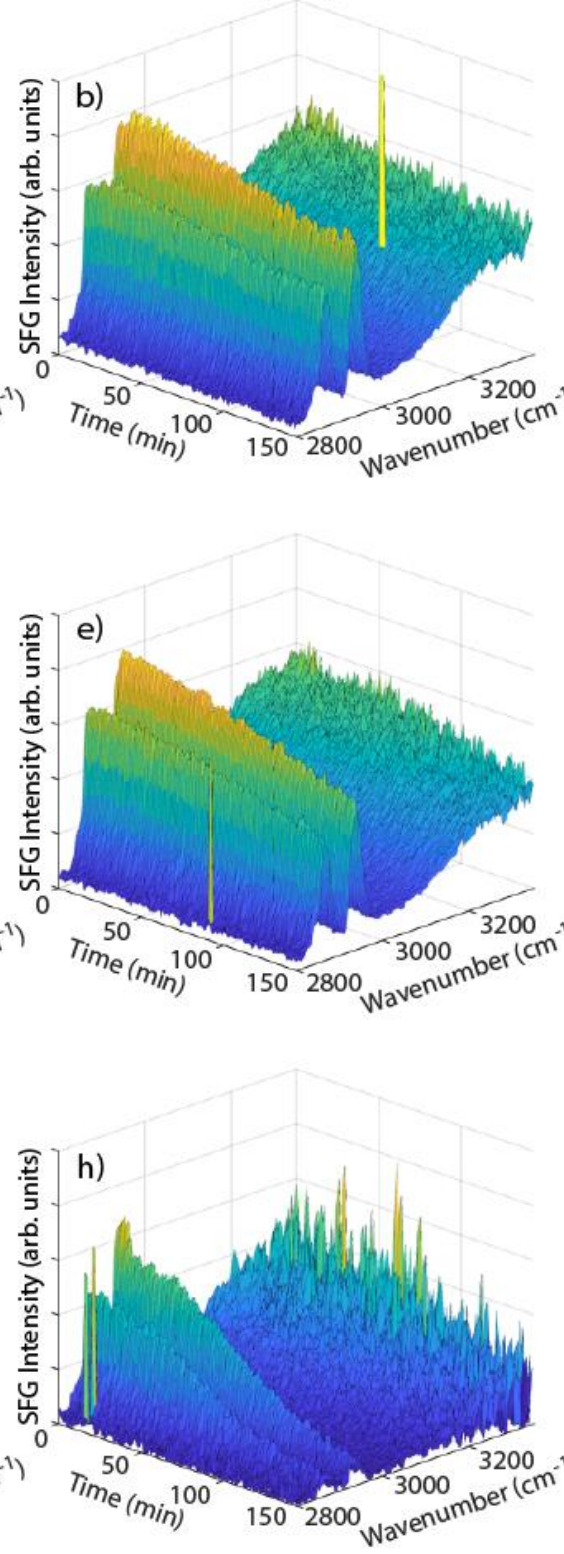

$\mathrm{Co}^{2+}:$ DEHPA

$(1: 2)$
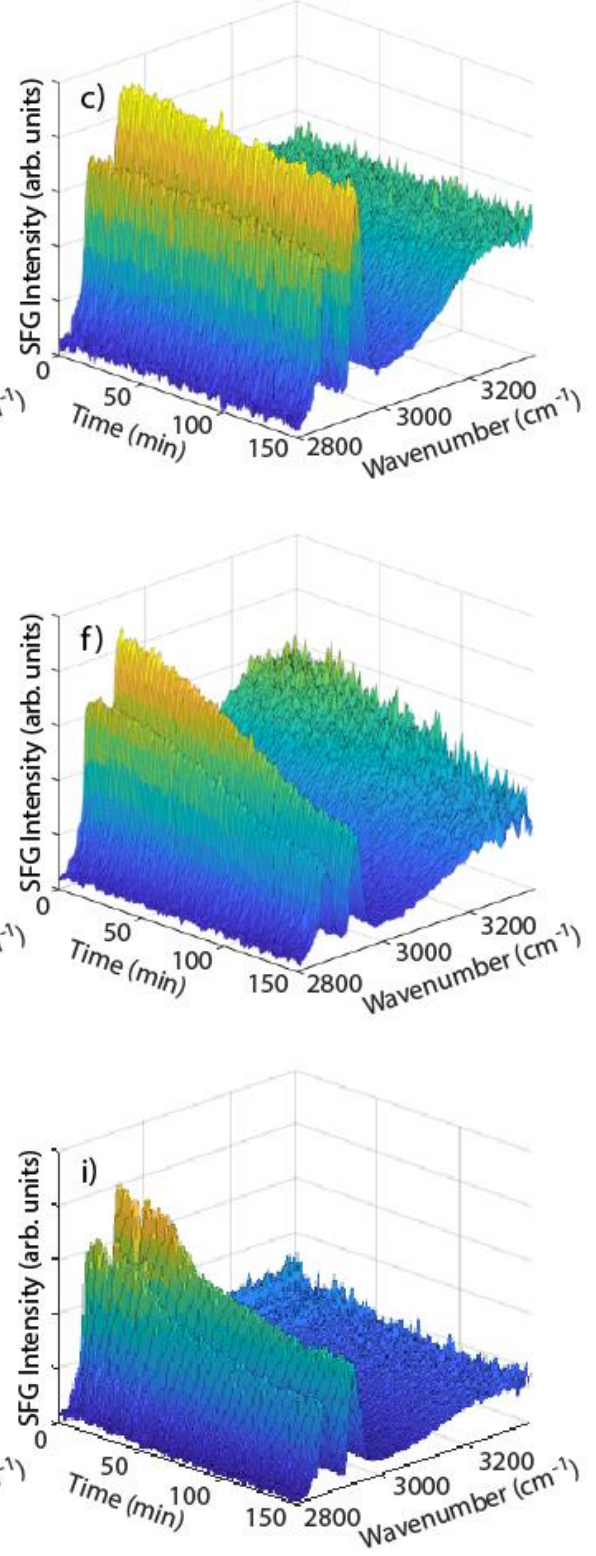

Figure 8 Kinetic SFG measurements are shown in a)-i) at different $\mathrm{pHs}$ (rows) and [Co $\left.{ }^{2+}\right]$ :[DEHPA] ratios (columns). Notably different kinetics are observed in each instance - in some cases higher order kinetics are observed and are indicative of dynamics of self-assembly as described in the main text.

the species that must ultimately be transported to the oil phase during extraction. We hypothesize that larger aggregates should have a harder time leaving the surface due to the difficulty in choreographing the concerted motions of many molecular units and their associated solvation shells to form a micelle.

To explore this hypothesis, we more carefully consider the interfacial kinetics at a range of $\mathrm{pHs}$ and $\mathrm{Co}^{2+}$ concentrations. One would expect based on phenomenological kinetics that the rate of signal loss, presumably (for now) due to extraction, should increase with increasing concentrations of reagents $\left(\mathrm{Co}^{2+}\right.$ in this case). However, at $\mathrm{pH} 5.5$, increasing the $\mathrm{Co}^{2+}$ concentration slows down the apparent rate, whereas at $\mathrm{pH} 4$ the rate increases, and at $\mathrm{pH} 3$, the rate is only moderately affected. To rationalize these seemingly strange kinetic results, recall that at $\mathrm{pH} 5.5$ the neat interface is composed of well-ordered water-bridged aggregates. On complexation with $\mathrm{Co}^{2+}$ the interfacial water/protons/sodium species are replaced with $\mathrm{Co}^{2+}$ ions to form metal-bridged aggregates at the interface (evidence from the ordering of ligands at $\mathrm{pH} 4$ in the presence of $\mathrm{Co}^{2+}$ ). Increasing the concentration of $\mathrm{Co}^{2+}$ could then yield extended metal bridged aggregates that are formed via substitution into the already established water bridged structure. These larger aggregates should be correspondingly harder to desorb into the oil phase via micelle formation based on their size. This is to say, larger fluctuations in the L/L phase boundary are necessary to facilitate the transport of a highly loaded aggregate ${ }^{35,44-45}$ and thus would be accompanied by a slower apparent rate constant, as observed in our time resolved SFG data. Correspondingly, at $\mathrm{pH} 4$, where no 


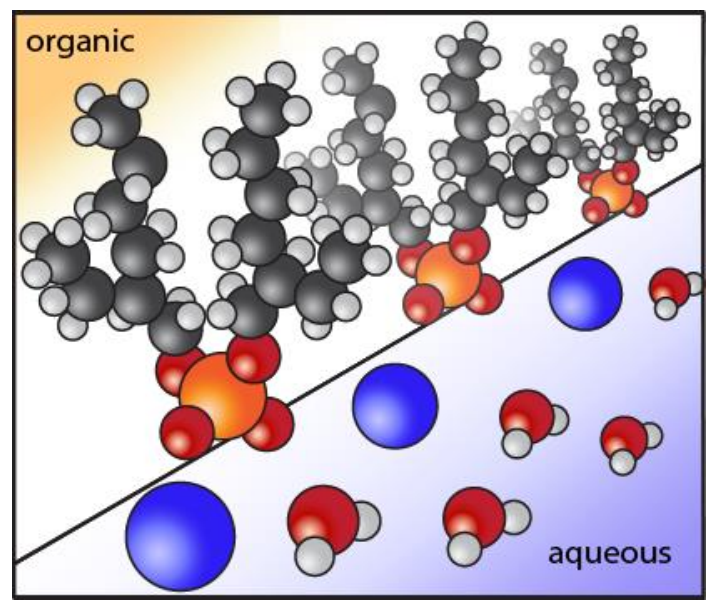

Figure 9: Cartoon of the buried L/L interface during the extraction of $\mathrm{Co}^{2+}$ (Blue spheres). The $\mathrm{Co}^{2+}$ ions effectively substitute into the H-bonding network and can potentially flip the orientation of nearby water molecules (compare to Fig. 7).

ordering was observed at the neat interface, the apparent rate increases with higher $\mathrm{Co}^{2+}$ concentrations. This is expected since there was no pre-assembly of a water-bridged aggregate at the neat interface and little to no interfacial ordering. In this case, the $\mathrm{Co}^{2+}$ has to complex with the ligands at the surface, order/assemble into interfacial aggregates and then possibly extract. In fact, the first step in extraction at high $\left[\mathrm{Co}^{2+}\right]:[\mathrm{DEHPA}]$ ratios at $\mathrm{pH} 4$ is the formation of interfacial aggregates as suggested by more complex kinetic features and clear evidence of $\mathrm{Co}^{2+}$ driven ordering. At $\mathrm{pH} 3$, the rate doesn't change very much with $\mathrm{Co}^{2+}$ concentration. This is presumably because at low $\mathrm{pHs}$ the presence of excess interfacial protons inhibits the formation of interfacial aggregates. This is supported by independent measurements of the interfacial surface tension at different pHs and $\left[\mathrm{Co}^{2+}\right.$ :[DEHPA] ratios that are shown in the supporting information in Fig. S6. These results show distinct surface tensions as the $\left[\mathrm{Co}^{2+}\right]:[\mathrm{DEHPA}]$ ratio is changed that indicate the presence of different interfacial species in each scenario. Notably, at the highest $\left[\mathrm{Co}^{2+}\right]:[\mathrm{DEHPA}]$ ratio $(1: 2)$ there is a measurable difference between the surface tensions measured at $\mathrm{pH} 5.5$, and 4.0, again, indicating the presence of structurally/chemically distinct interfacial species in support of the SFG measurements. The decrease in surface tension with $\left[\mathrm{Co}^{2+}\right]$ :[DEHPA] ratio can be explained by noting that the interfacial aggregates are likely linear chains (see Fig. 7 and 9) given the bulkiness of the tail groups and that interactions between the chains are not essential for micelle formation via the aforementioned mechanisms.

The formation of interfacial aggregates and the known transport of metal species via micelles means that the decay in the SFG signal is not necessarily due to extraction, as one would intuitively think, but could also originate from the formation of centrosymmetric interfacial species. For instance, the presence of interfacial micelles or bi/multilayers would decrease the overall SFG signal due to the cancelation of signals arising from increasing symmetry. ${ }^{60,76}$ As such, based on the discussion so far, we cannot definitively assign the kinetics to extraction, but must consider it a combination of extraction and loss of interfacial asymmetry.
To address the possible difference in mechanism for the SFG decay, we note that the complexation of $\mathrm{Co}^{2+}$ with the interfacial ligands should result in the alteration of the surface potential seen by nearby water molecules. ${ }^{59-60,77-78}$ Specifically, at the neat interfaces $\mathrm{H}^{+}$or $\mathrm{Na}^{+}$are the counter ions available to screen charges and facilitate interfacial aggregation. On replacing these ions with the more highly charged $\mathrm{Co}^{2+}$ species interfacial potential would change and, based on other measurements, could flip the water orientation, as sketched in Fig. 9. While we do not measure the up/down orientation of water at these interfaces, we do measure the effect of the surface potential on the interfacial water via $\phi{ }^{59} \mathrm{~A}$ time-evolving phase angle is therefore indicative of a changing surface potential and a growing aggregate structure. A limiting case, where the decrease in SFG signal is accompanied by a change in phase angle, is suggestive of the formation of interfacial species that are more centrosymmetric but generate a different overall surface charge density. In other words, a change in $\phi$ that is accompanied by a change in signal amplitudes suggest that the decrease in SFG signal arises from the formation of a more centrosymmetric species at the interface. This is because the accumulation of surface charge can evolve independently of the symmetry of the interfacial species since the associated electrostatic field extends into the aqueous phase and polarizes bulk water molecules. In contrast, a time evolving SFG signal that is not accompanied by a changing phase angle indicates that the surface potential is static and that changes in the SFG signals results from varying interfacial populations and therefore corresponds to extraction.

To obtain this needed information from the data in Fig. 8 , we fit each time resolved spectral data to a simplified spectral model containing three resonances, which includes the $\mathrm{CH}_{3}$-SS, FR and -OH modes, a fixed non-resonant background and variable phase angle. Allowing the non-resonant background response to vary provided similar results but with larger fit uncertainties due to correlations between the non-resonant background and the phase angle. The extracted phase angles are plotted in Fig. 10 along with mode specific amplitudes scaled by the associated widths for representative $\left[\mathrm{Co}^{2+}\right]$ :[DEHPA] ratios and $\mathrm{pH}$ regimes, as indicated in the legend. The ratio, $\mathrm{A}_{\mathrm{q}} / \Gamma_{\mathrm{q}}$, serves to ensure that potential peak broadening/narrowing is accounted for ${ }^{79-81}$ and that the extracted values describe the interfacial population, orientation and structure. We focus our analysis on the data obtained at $\mathrm{pH} 4$ and 5.5 at $\left[\mathrm{Co}^{2+}\right]$ :[DEHPA] ratios of $1: 2$ and $1: 8$, since they represent the extremes in the presented kinetics. The insight obtained from these results agrees with measurements made at different conditions that are not explicitly discussed.

Considering the data presented in Fig. 10, we start our discussion by noting that the scaled amplitudes at early times depend on $\mathrm{pH}$ and $\left[\mathrm{Co}^{2+}\right]:[\mathrm{DEHPA}]$ ratios. Specifically, the - $\mathrm{CH}_{3}$-SS modes plotted in Fig. 10a are found to be $\sim 15 \%$ smaller at pH 5.5, 1:8 [ $\left.\mathrm{Co}^{2+}\right]$ :[DEHPA] vs. at other conditions. This difference suggests that the orientation and/or structure of the interface immediately following contact differs at pH 5.5 1:8 from the other experiments. This is because 

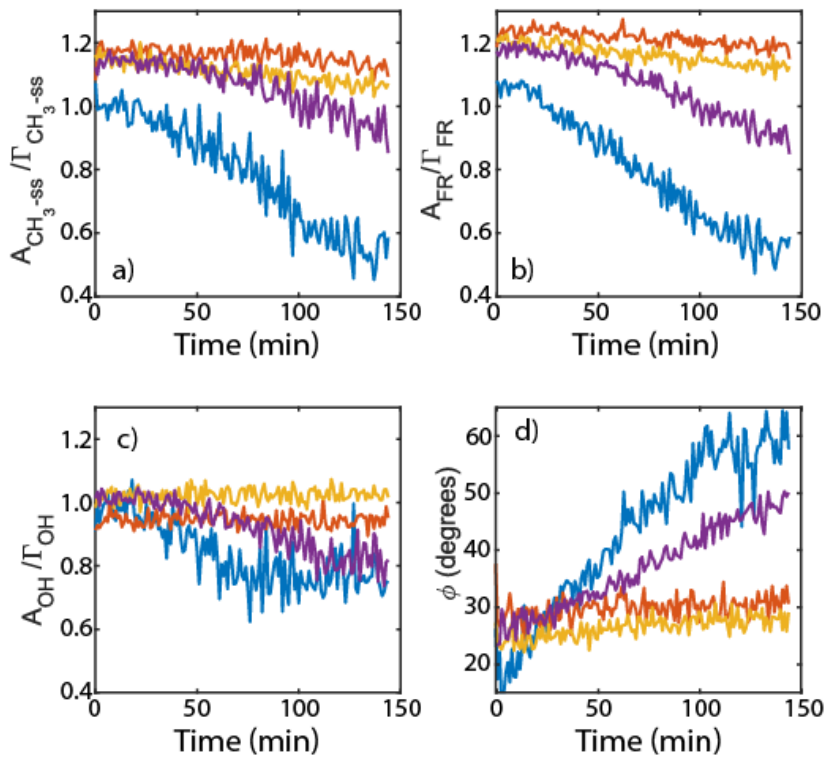

$-\mathrm{pH} 5.5,1: 8-\mathrm{pH} 4,1: 8$

$-\mathrm{pH} 5.5,1: 2-\mathrm{pH} 4,1: 2$

Figure 10: Transient SFG signals for methyl symmetric stretch (a) and the Fermi resonance (b) of DEHPA vs. time during extraction of $\mathrm{Co}^{2+}$. The signal from $-\mathrm{OH}$ stretches of interfacial water is plotted in (c) whereas the extracted phase angle is shown in (d).

the population of DEHPA reached its maximum around $\mathrm{pH}$ 5.5, as determined from static measurements in Fig. 4a where the neat interface was saturated with ligands. This means that the interfacial layer immediately exchanges ions to form a $\mathrm{Co}^{2+}$ coordinating aggregates. This is supported by signals at $\mathrm{pH} 4$ at early times that show ordered DEHPA in the presence of $\mathrm{Co}^{2+}$ whereas no ordering was found at the neat interface. The FR signals are plotted in Fig. 10b and differ in all four measurements. The differences in early time FR signals suggests different intermolecular interactions, which FR modes are exquisitely sensitive to, that might play a role in the organization of the interface. ${ }^{82}$ Similarly, the signals arising from interfacial water, as measured by $-\mathrm{OH}$ stretches in Fig.10c, show no obvious differences at early times. This suggests that the water organizes very quickly, presumably on a commensurate timescale to initial $\mathrm{Co}^{2+}$ complexation. The early time phase angles, plotted in Fig. $10 \mathrm{~d}$, are also very similar across experiments, which indicate the overall surface charge at early times is similar, at least on a qualitative level.

Considering next the time dependence of the phase angle in Fig. 10d we find a dramatic evolution for the case of $\mathrm{pH} \quad 5.5,1: 8 \quad\left[\mathrm{Co}^{2+}\right]:[\mathrm{DEHPA}]$ and for $\mathrm{pH} 5.5,1: 2$ $\left[\mathrm{Co}^{2+}\right]:[\mathrm{DEHPA}]$ regimes. The phase angle hardly changes

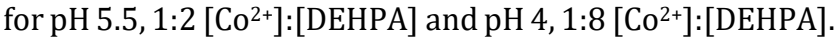
Based on the logic detailed above, a change in the phase angle describes a time evolving surface potential due to $\mathrm{Co}^{2+}$ complexation. This means that the decay in the signal for $\mathrm{pH}$ 5.5, $1: 8\left[\mathrm{Co}^{2+}\right]:[\mathrm{DEHPA}]$ and $\mathrm{pH} 4,1: 2\left[\mathrm{Co}^{2+}\right]:[\mathrm{DEHPA}]$ is likely due to the formation of centrosymmetric species at the L/L phase boundary - be it a bi/multilayer, micellar, ${ }^{35}$ or 'finger-like' structures, ${ }^{39,72-73}$ but with different amounts of $\mathrm{Co}^{2+}$ coordinated. This makes intuitive sense since at the pH 5.5, 1:8 [ $\left.\mathrm{Co}^{2+}\right]$ :[DEHPA] ratio the interface should consist of smaller aggregates that can more easily form a micelle or related structures via the budding mechanism previously described. ${ }^{35}$ Similarly, at $\mathrm{pH} 4$, there was little to no ordering at the neat interface - however, at higher $\left[\mathrm{Co}^{2+}\right]$ :[DEHPA] ratios, the $\mathrm{Co}^{2+}$ bridges DEHPA into aggregates that can then transform into interfacial micelles/multilayers. In contrast, if the aggregate is too large, as is expected for $\mathrm{pH} 5.5,1: 2\left[\mathrm{Co}^{2+}\right]$ :[DEHPA] the species will struggle to form more complex centrosymmetric structures that can generate free space at the interface for more DEHPA to adsorb and for more $\mathrm{Co}^{2+}$ to complex. This effect is reflected by the slow apparent kinetics. At $\mathrm{pH} 4,1: 8\left[\mathrm{Co}^{2+}\right.$ : [DEHPA], there is apparently not enough $\mathrm{Co}^{2+}$ to form an appropriately sized aggregate to facilitate the growth of surface-localized centrosymmetric structures. As such, for both cases exhibiting slow kinetics, the surface charge is determined almost immediately on contact, and does not change with time. These results then suggest that the time-dependence observed in SFG signals originates from the formation of centrosymmetric interfacial structures that can subsequently extract to the oil phase. Of note, at $\mathrm{pH} 3$ there is never a change in phase angle during extraction regardless of the $\left[\mathrm{Co}^{2+}\right]$ :[DEHPA] ratio, which indicates that the mechanism for extraction at lower pHs is different and does not rely on the formation of interfacial structures in the same way as at higher $\mathrm{pHs}$.

In general, these results suggest that selectivity and transport are determined by interactions at the interface with a pre-assembled aggregate that subsequently exchanges ions to form a chemically distinct interfacial species. The exchange of water/protons/sodium with $\mathrm{Co}^{2+}$ changes the chemical makeup as well as the surface potential - this means that the structure and composition of the extracted species at high $\left[\mathrm{Co}^{2+}\right]$ :[DEHPA] should be, and in fact are, ${ }^{75}$ different depending on the exact experimental conditions. This result also points to a new design principle for chemical separations: one must effectively tune the surface potential to build/modify H-bonding networks to favor the assembly of ligands into aggregates where ions can be easily exchanged - in turn the change in the surface potential due to divalent ion complexation should generate a new H-bonding network that promotes micelle formation thereby facilitating transport into the oil phase.

\section{CONCLUSIONS}

We have shown, using vibrational SFG spectroscopy, how the interfacial layer separating bulk oil and water phases mediates chemical separations in the context of liquid extraction. In the absence of divalent cations, the bulk aqueous phase $\mathrm{pH}$ mediates the assembly of 'polymer-like' molecular aggregates at the interface that are linked via $\mathrm{H}$ bonding in the aqueous phase. Changing the bulk pH effectively tunes what species are present at the interface: either molecular species at low pHs or larger aggregates at higher pHs where extraction efficiencies peak. These interfacial aggregates are hypothesized to be precursors to micelles, which are the vehicle for extraction. To test this hypothesis, we performed time resolved SFG measurements that tracked the interface and subsequent extraction/assembly kinetics in real-time. Based on our measurements, there is a clear change in the mechanisms by which extraction occurs 
as a function of $\mathrm{pH}$. At low $\mathrm{pH}$, the molecular species dominate the interface and the kinetics are nearly invariant with $\left[\mathrm{Co}^{2+}\right]:[\mathrm{DEHPA}]$ ratio. Increasing the $\mathrm{pH}$ shows counter intuitive kinetics in that the addition of more $\mathrm{Co}^{2+}$ slows down in the apparent kinetics. This is explained by the formation of larger interfacial aggregates that are created by facile substitution into a pre-arranged interfacial layer that was setup via $\mathrm{H}$-bonding in the aqueous phase. The change in surface potential observed in time suggests that the decay kinetics represent a combination of both extraction and self-assembly into centrosymmetric intermediate structures localized at the interface. The mechanisms of liquid extractions are therefore mediated by the formation and dissociation of these species at/from the interface.

Future work might focus on kinetics at low $\left[\mathrm{Co}^{2+}\right]:[\mathrm{DEHPA}]$ ratios to understand what structural and chemical changes accompany/drive the cross over in extraction behavior between regimes. Also, specific ion effects in the formation of the interfacial species at variable $\mathrm{pHs}$ could be explored as an important step in understanding extraction in complex mixtures ${ }^{11}$ and binding at mineral interfaces. ${ }^{53}$

\section{EXPERIMENTAL}

\section{Materials}

Aqueous phases were prepared using ultrapure water and appropriate electrolytes/ions; the $\mathrm{pH}$ of each solution was adjusted using concentrated acids or bases and measured with a calibrated $\mathrm{pH}$ meter immediately before experiments. All chemicals were purchased from Sigma-Aldrich and used without further purification.

\section{SFG Measurements}

A sketch of the SFG spectrometer and sample geometry is provided in the Supporting Information. Briefly, an amplified femtosecond Ti:sapphire laser system (Spectra Physics Spitfire Pro) was used to produce $\sim 40$ fs pulses of $\sim 800 \mathrm{~nm}$ near-infrared (NIR) light with average powers greater than $6 \mathrm{~W}$ at a $1 \mathrm{kHz}$ repetition rate. The output beam was split into two arms. One path was aligned into an optical parametric amplifier with difference frequency mixer to produce mid-infrared (IR) light centered near $2900 \mathrm{~cm}^{-1}$ or $3125 \mathrm{~cm}^{-1}$, depending on the spectral window of interest. The other path was directed to a $4 f$-pulse shaper equipped with a spatial light modulator to generate narrowband upconversion pulses. ${ }^{83-84}$ The polarizations of both paths were purified and rotated with appropriate polarizers/waveplates. The IR and stretched NIR arms were colinearly combined with a dichroic optic then focused on the sample at a $60^{\circ}$ angle relative to the surface normal. The radiated light was collected via an achromatic lens, polarization resolved and spectrally filtered. The light was routed to a spectrograph equipped with a CCD camera that was used for detection. The radiated SFG intensity is proportional to the absolute square of the effective second-order susceptibility, $\chi_{\text {eff }}{ }^{(2)}$, and the incident laser fields, $\left(E_{I R}\right.$ and $\left.E_{N I R}\right)$ according to:

$$
I_{\mathrm{SFG}} \propto\left|\chi_{\mathrm{eff}}^{(2)} E_{I R} E_{N I R}\right|^{2}
$$

The effective second-order nonlinear susceptibility, is the sum of a resonant, $\chi_{\mathrm{res}}^{(2)}$, and a non-resonant, $\chi_{\mathrm{NR}}^{(2)}$, contribution that takes the form: ${ }^{51,85}$

$$
\chi_{\mathrm{eff}}^{(2)}=\chi_{\mathrm{NR}}^{(2)} e^{i \phi}+\chi_{\mathrm{res}}^{(2)}=\chi_{\mathrm{NR}}^{(2)} e^{i \phi}+\sum_{q} \frac{A_{q}}{\omega_{\mathrm{IR}}-\omega_{q}+i \Gamma_{q}}
$$

where $\omega_{I R}$ are frequency components in the IR pulse, $A_{q}$ is the fit amplitude, $\omega_{q}$ is the transition frequency, $\Gamma_{q}$ is the linewidth for the $q^{\text {th }}$-mode, and $\phi$ is the phase angle. ${ }^{59}$ Spectral parameters, including peak positions, amplitudes, and linewidths were extracted from the data by fitting to Equations 1 and 2. A summary of curve fitting results is supplied in the Supporting Information. SFG spectra were collected in different polarization combinations - following convention, the letters describing the polarizations correspond to the radiated SFG, NIR, and IR polarizations, respectively. ${ }^{51,85}$

\section{ASSOCIATED CONTENT}

\section{Supporting Information}

Contains an illustration of the experimental setup and sample geometry, tables with fitting parameters, surface tension data. light scattering data, extraction results, control kinetic data.

\section{AUTHOR INFORMATION}

\section{Corresponding Author}

*doughtybl@ornl.gov

\section{ORCID}

Azhad U. Chowdhury - 0000-0002-6735-815X

Lu Lin - 0000-0003-1308-9158

Benjamin Doughty - 0000-0001-6429-9329

\section{Author Contributions}

A.U.C., L.L. and B.D. contributed to all aspects of this work. All authors have given approval to the final version of the manuscript.

\section{Funding Sources}

This work was supported by the U.S. Department of Energy, Office of Science, Basic Energy Sciences, Chemical Sciences, Geosciences, and Biosciences Division.

\section{ACKNOWLEDGMENT}

B.D. would like to thank Dr. Bruce A. Moyer and Dr. Philip F. Britt for suggesting this research direction and noting the importance of interfaces in liquid extractions. B.D. would also like to thank Prof. Tessa R. Calhoun, Dr. Robert L. Sacci and Dr. Vyacheslav S. Bryantsev for relentless feedback on the manuscript and figures. The authors acknowledge Dr. Vera Bocharova who kindly performed dynamic light scattering measurements.

\section{REFERENCES}


1. National Academies of Sciences, E.; Medicine, A Research Agenda for Transforming Separation Science. The National Academies Press: Washington, DC, 2019; p 114.

2. Cheisson, T.; Schelter, E. J., Rare earth elements: Mendeleev's bane, modern marvels. Science 2019, 363 (6426), 489-493.

3. Izatt, R. M.; Izatt, S. R.; Bruening, R. L.; Izatt, N. E.; Moyer, B. A., Challenges to achievement of metal sustainability in our high-tech society. Chemical Society Reviews 2014, 43 (8), 24512475.

4. Sholl, D. S.; Lively, R. P., Seven chemical separations to change the world. Nature 2016, 532 (7600), 435-437.

5. Brethomé, F. M.; Williams, N. J.; Seipp, C. A.; Kidder, M. K.; Custelcean, R., Direct air capture of $\mathrm{CO} 2$ via aqueous-phase absorption and crystalline-phase release using concentrated solar power. Nature Energy 2018, 3 (7), 553-559.

6. Williams, N. J.; Seipp, C. A.; Brethomé, F. M.; Ma, Y.-Z.; Ivanov, A. S.; Bryantsev, V. S.; Kidder, M. K.; Martin, H. J.; Holguin, E.; Garrabrant, K. A.; Custelcean, R., CO2 Capture via Crystalline Hydrogen-Bonded Bicarbonate Dimers. Chem 2019, 5 (3), 719-730.

7. Ma, Y.; Zhang, F.; Lively, R. P., Chapter 3 - Manufacturing Nanoporous Materials for Energy-Efficient Separations: Application and Challenges. In Sustainable Nanoscale Engineering, Szekely, G.; Livingston, A., Eds. Elsevier: 2020; pp 33-81.

8. Wilmer, C. E.; Leaf, M.; Lee, C. Y.; Farha, O. K.; Hauser, B. G.; Hupp, J. T.; Snurr, R. Q., Large-scale screening of hypothetical metal-organic frameworks. Nature Chemistry 2012, 4 (2), 83-89.

9. Li, J.-R.; Sculley, J.; Zhou, H.-C., Metal-Organic Frameworks for Separations. Chemical Reviews 2012, 112 (2), 869-932.

10. Moyer, B. A., Ion Exchange and Solvent Extraction: Volume 23, Changing the Landscape in Solvent Extraction. 1st ed.; CRC Press: Boca Raton, Fl, 2019; Vol. 23.

11. Špadina, M.; Bohinc, K.; Zemb, T.; Dufrêche, J.-F., Synergistic Solvent Extraction Is Driven by Entropy. ACS Nano 2019, 13 (12), 13745-13758.

12. Špadina, M.; Bohinc, K.; Zemb, T.; Dufrêche, J.-F., Colloidal Model for the Prediction of the Extraction of Rare Earths Assisted by the Acidic Extractant. Langmuir 2019, 35 (8), 3215-3230.

13. Ion Exchange and Solvent Extraction Supramolecular Aspects of Solvent Extraction. CRC Press: 2014; Vol. 21.

14. Mazzola, P. G.; Lopes, A. M.; Hasmann, F. A.; Jozala, A. F.; Penna, T. C.; Magalhaes, P. O.; Rangel-Yagui, C. O.; Jr, A. P., Liquid-liquid extraction of biomolecules: an overview and update of the main techniques. Journal of Chemical Technology \& Biotechnology 2008, 83 (2), 143-157.

15. Kolesnichenko, I. V.; Anslyn, E. V., Practical applications of supramolecular chemistry. Chem. Soc. Rev. 2017, 46 (9), 23852390.

16. Xie, F.; Zhang, T. A.; Dreisinger, D.; Doyle, F., A critical review on solvent extraction of rare earths from aqueous solutions. Minerals Engineering 2014, 56, 10-28.

17. Thakur, N. V., Separation of Rare Earths by Solvent Extraction. Mineral Processing and Extractive Metallurgy Review 2000, 21 (1-5), 277-306.

18. Belova, V. V., Development of solvent extraction methods for recovering rare earth metals. Theoretical Foundations of Chemical Engineering 2017, 51 (4), 599-609.

19. Veliscek-Carolan, J., Separation of actinides from spent nuclear fuel: A review. Journal of Hazardous Materials 2016, 318, 266-281.

20. Zhu, Z.; Pranolo, Y.; Cheng, C. Y., Separation of uranium and thorium from rare earths for rare earth production - A review. Minerals Engineering 2015, 77, 185-196.

21. Kim, I.-G.; Kim, S.-S.; Kim, G.-N.; Han, G.-S.; Choi, J.-W., Reduction of Radioactive Waste from Remediation of Uranium-
Contaminated Soil. Nuclear Engineering and Technology 2016, 48 (3), 840-846

22. Cremer, P. S.; Flood, A. H.; Gibb, B. C.; Mobley, D. L., Collaborative routes to clarifying the murky waters of aqueous supramolecular chemistry. Nature Chemistry 2018, 10 (1), 8-16.

23. Sharma, V. K.; Mitra, S.; Mukhopadhyay, R., Dynamic Landscape in Self-Assembled Surfactant Aggregates. Langmuir 2019, 35 (44), 14151-14172.

24. Piradashvili, K.; Alexandrino, E. M.; Wurm, F. R.; Landfester, K., Reactions and Polymerizations at the Liquid-Liquid Interface. Chemical Reviews 2016, 116 (4), 2141-2169.

25. Motokawa, R.; Kobayashi, T.; Endo, H.; Mu, J.; Williams, C. D.; Masters, A. J.; Antonio, M. R.; Heller, W. T.; Nagao, M., A Telescoping View of Solute Architectures in a Complex Fluid System. ACS Central Science 2019, 5 (1), 85-96.

26. Robertson, E. J.; Richmond, G. L., Chunks of Charge: Effects at Play in the Assembly of Macromolecules at Fluid Surfaces. Langmuir 2013, 29 (35), 10980-10989.

27. Schabes, B. K.; Altman, R. M.; Richmond, G. L., Come Together: Molecular Details into the Synergistic Effects of Polymer-Surfactant Adsorption at the Oil/Water Interface. The Journal of Physical Chemistry B 2018, 122 (36), 8582-8590.

28. Robertson, E. J.; Richmond, G. L., Molecular Insights in the Structure and Layered Assembly of Polyelectrolytes at the Oil/Water Interface. The Journal of Physical Chemistry C 2014, 118 (49), 28331-28343.

29. Beaman, D. K.; Robertson, E. J.; Richmond, G. L., Ordered polyelectrolyte assembly at the oil-water interface. Proceedings of the National Academy of Sciences 2012, 109 (9), 3226-3231.

30. Chen, Y.; Jena, K. C.; Roke, S., From Hydrophobic to Hydrophilic: The Structure and Density of the Hexadecane Droplet/Alkanol/Water Interface. The Journal of Physical Chemistry C 2015, 119 (31), 17725-17734.

31. Olenick, L. L.; Troiano, J. M.; Smolentsev, N.; Ohno, P. E.; Roke, S.; Geiger, F. M., Polycation Interactions with Zwitterionic Phospholipid Monolayers on Oil Nanodroplet Suspensions in Water (D2O) Probed by Sum Frequency Scattering. The Journal of Physical Chemistry B 2018, 122 (19), 5049-5056.

32. Scheu, R.; Chen, Y.; de Aguiar, H. B.; Rankin, B. M.; BenAmotz, D.; Roke, S., Specific Ion Effects in Amphiphile Hydration and Interface Stabilization. Journal of the American Chemical Society 2014, 136 (5), 2040-2047.

33. Chowdhury, A. U.; Taylor, G. J.; Bocharova, V.; Sacci, R. L.; Luo, Y.; McClintic, W. T.; Ma, Y.-Z.; Sarles, S. A.; Hong, K.; Collier, C. P.; Doughty, B., Insight into the Mechanisms Driving the Self-Assembly of Functional Interfaces: Moving from Lipids to Charged Amphiphilic Oligomers. Journal of the American Chemical Society 2020, 142 (1), 290-299.

34. Bu, W.; Yu, H.; Luo, G.; Bera, M. K.; Hou, B.; Schuman, A. W.; Lin, B.; Meron, M.; Kuzmenko, I.; Antonio, M. R., Observation of a rare earth ion-extractant complex arrested at the oil-water interface during solvent extraction. The Journal of Physical Chemistry B 2014, 118 (36), 10662-10674.

35. Liang, Z.; Bu, W.; Schweighofer, K. J.; Walwark, D. J.; Harvey, J. S.; Hanlon, G. R.; Amoanu, D.; Erol, C.; Benjamin, I.; Schlossman, M. L., Nanoscale view of assisted ion transport across the liquid-liquid interface. Proceedings of the National Academy of Sciences 2019, 116 (37), 18227-18232.

36. Scoppola, E.; Watkins, E.; Li Destri, G.; Porcar, L.; Campbell, R. A.; Konovalov, O.; Fragneto, G.; Diat, O., Structure of a liquid/liquid interface during solvent extraction combining X-ray and neutron reflectivity measurements. Physical Chemistry Chemical Physics 2015, 17 (23), 15093-15097.

37. Scoppola, E.; Watkins, E. B.; Campbell, R. A.; Konovalov, O.; Girard, L.; Dufrêche, J. F.; Ferru, G.; Fragneto, G.; Diat, O., Solvent extraction: Structure of the liquid-liquid interface 
containing a diamide ligand. Angewandte Chemie International Edition 2016, 55 (32), 9326-9330.

38. Micciulla, S.; Gerelli, Y.; Campbell, R. A.; Schneck, E., A Versatile Method for the Distance-Dependent Structural Characterization of Interacting Soft Interfaces by Neutron Reflectometry. Langmuir 2018, 34 (3), 789-800.

39. Qiao, B.; Muntean, J. V.; Olvera de la Cruz, M.; Ellis, R. J., Ion Transport Mechanisms in Liquid-Liquid Interface. Langmuir 2017, 33 (24), 6135-6142.

40. Servis, M. J.; Tormey, C. A.; Wu, D. T.; Braley, J. C., A Molecular Dynamics Study of Tributyl Phosphate and Diamyl Amyl Phosphonate Self-Aggregation in Dodecane and Octane. The Journal of Physical Chemistry B 2016, 120 (10), 2796-2806.

41. Karnes, J. J.; Benjamin, I., Miscibility at the immiscible liquid/liquid interface: A molecular dynamics study of thermodynamics and mechanism. The Journal of Chemical Physics 2018, 148 (3), 034707.

42. Karnes, J. J.; Villavicencio, N.; Benjamin, I., Transfer of an erbium ion across the water/dodecane interface: Structure and thermodynamics via molecular dynamics simulations. Chemical Physics Letters 2019, 737, 136825.

43. Ghadar, Y.; Parmar, P.; Samuels, A. C.; Clark, A. E., Solutes at the liquid:liquid phase boundary-Solubility and solvent conformational response alter interfacial microsolvation. The Journal of Chemical Physics 2015, 142 (10), 104707.

44. Zhou, T.; McCue, A.; Ghadar, Y.; Bakó, I.; Clark, A. E., Structural and Dynamic Heterogeneity of Capillary Wave Fronts at Aqueous Interfaces. The Journal of Physical Chemistry B 2017, 121 (38), 9052-9062.

45. Servis, M. J.; Clark, A. E., Surfactant-enhanced heterogeneity of the aqueous interface drives water extraction into organic solvents. Physical Chemistry Chemical Physics 2019, 21 (6), 28662874.

46. Ganguli, R.; Cook, D. R., Rare earths: A review of the landscape. MRS Energy \& Sustainability 2018, 5, E9.

47. Eggert, R.; Wadia, C.; Anderson, C.; Bauer, D.; Fields, F.; Meinert, L.; Taylor, P., Rare earths: market disruption, innovation, and global supply chains. Annual Review of Environment and Resources 2016, 41, 199-222.

48. Nassar, N. T.; Graedel, T. E.; Harper, E. M., By-product metals are technologically essential but have problematic supply. Science Advances 2015, 1 (3), e1400180.

49. Omelchuk, K.; Szczepański, P.; Shrotre, A.; Haddad, M.; Chagnes, A., Effects of structural changes of new organophosphorus cationic exchangers on a solvent extraction of cobalt, nickel and manganese from acidic chloride media. RSC Advances 2017, 7 (10), 5660-5668.

50. Ibrahim, T. H., An Overview of the Physiochemical Nature of Metal-Extractant Species in Organic Solvent/Acidic Organophosphorus Extraction Systems. Separation Science and Technology 2011, 46 (14), 2157-2166.

51. Wang *, H.-F.; Gan $\uparrow+$, W.; Lu $\uparrow+\S, \mathrm{R}$.; Rao $\uparrow+$ ๆ, Y.; Wu $\uparrow$, B.-H., Quantitative spectral and orientational analysis in surface sum frequency generation vibrational spectroscopy (SFG-VS). International Reviews in Physical Chemistry 2005, 24 (2), 191-256. 52. Lu, R.; Gan, W.; Wu, B.-h.; Zhang, Z.; Guo, Y.; Wang, H.-f., $\mathrm{C}-\mathrm{H}$ Stretching Vibrations of Methyl, Methylene and Methine Groups at the Vapor/Alcohol $(\mathrm{n}=1-8)$ Interfaces. The Journal of Physical Chemistry B 2005, 109 (29), 14118-14129.

53. Wanhala, A. K.; Doughty, B.; Bryantsev, V. S.; Wu, L.; Mahurin, S. M.; Jansone-Popova, S.; Cheshire, M. C.; Navrotsky, A.; Stack, A. G., Adsorption mechanism of alkyl hydroxamic acid onto bastnäsite: Fundamental steps toward rational collector design for rare earth elements. Journal of Colloid and Interface Science 2019, 553, 210-219.
54. Barrett, A.; Petersen, P. B., Order of Dry and Wet MixedLength Self-Assembled Monolayers. The Journal of Physical Chemistry C 2015, 119 (42), 23943-23950.

55. Doughty, B.; Genix, A.-C.; Popov, I.; Li, B.; Zhao, S.; Saito, T.; Lutterman, D. A.; Sacci, R. L.; Sumpter, B. G.; Wojnarowska, Z.; Bocharova, V., Structural correlations tailor conductive properties in polymerized ionic liquids. Physical Chemistry Chemical Physics 2019, 21 (27), 14775-14785.

56. Watson, B. R.; Ma, Y.-Z.; Cahill, J. F.; Doughty, B.; Calhoun, T. R., Probing ligand removal and ordering at quantum dot surfaces using vibrational sum frequency generation spectroscopy. Journal of Colloid and Interface Science 2019, 537, 389-395.

57. Weeraman, C.; Yatawara, A. K.; Bordenyuk, A. N.; Benderskii, A. V., Effect of Nanoscale Geometry on Molecular Conformation: Vibrational Sum-Frequency Generation of Alkanethiols on Gold Nanoparticles. Journal of the American Chemical Society 2006, 128 (44), 14244-14245.

58. Adams, E. M.; Verreault, D.; Jayarathne, T.; Cochran, R. E.; Stone, E. A.; Allen, H. C., Surface organization of a DPPC monolayer on concentrated $\mathrm{SrCl} 2$ and $\mathrm{ZnCl} 2$ solutions. Physical Chemistry Chemical Physics 2016, 18 (47), 32345-32357.

59. Ohno, P. E.; Wang, H.-f.; Geiger, F. M., Second-order spectral lineshapes from charged interfaces. Nature Communications 2017, $8(1), 1032$.

60. Eisenthal, K. B., Second Harmonic Spectroscopy of Aqueous Nano- and Microparticle Interfaces. Chemical Reviews 2006, 106 (4), 1462-1477.

61. Neuman, R. D.; Zhou, N.-F.; Wu, J.; Jones, M. A.; Gaonkar, A. G.; Park, S. J.; Agrawal, M. L., General Model for Aggregation of Metal-extractant Complexes in Acidic Organophosphorus Solvent Extraction Systems. Separation Science and Technology 1990, 25 (13-15), 1655-1674.

62. Wei, Z.; Piantavigna, S.; Holt, S. A.; Nelson, A.; Spicer, P. T.; Prescott, S. W., Comparing Surfactant Structures at "Soft" and "Hard" Hydrophobic Materials: Not All Interfaces Are Equivalent. Langmuir 2018, 34 (31), 9141-9152.

63. Zhang, T.; Brantley, S. L.; Verreault, D.; Dhankani, R.; Corcelli, S. A.; Allen, H. C., Effect of PH and Salt on Surface p K a of Phosphatidic Acid Monolayers. Langmuir 2018, 34 (1), 530539.

64. Dreier, L. B.; Nagata, Y.; Lutz, H.; Gonella, G.; Hunger, J.; Backus, E. H. G.; Bonn, M., Saturation of charge-induced water alignment at model membrane surfaces. Science Advances 2018, 4 (3), eaap7415.

65. Petersen, M. K.; Iyengar, S. S.; Day, T. J. F.; Voth, G. A., The Hydrated Proton at the Water Liquid/Vapor Interface. The Journal of Physical Chemistry B 2004, 108 (39), 14804-14806.

66. Tse, Y.-L. S.; Chen, C.; Lindberg, G. E.; Kumar, R.; Voth, G. A., Propensity of Hydrated Excess Protons and Hydroxide Anions for the Air-Water Interface. Journal of the American Chemical Society 2015, 137 (39), 12610-12616.

67. Bai, C.; Herzfeld, J., Surface Propensities of the Self-Ions of Water. ACS Central Science 2016, 2 (4), 225-231.

68. Knight, C.; Voth, G. A., The Curious Case of the Hydrated Proton. Accounts of Chemical Research 2012, 45 (1), 101-109.

69. Das, S.; Imoto, S.; Sun, S.; Nagata, Y.; Backus, E. H. G.; Bonn, M., Nature of Excess Hydrated Proton at the Water-Air Interface. Journal of the American Chemical Society 2020, 142 (2), 945-952. 70. Sengupta, S.; Moberg, D. R.; Paesani, F.; Tyrode, E., Neat Water-Vapor Interface: Proton Continuum and the Nonresonant Background. The Journal of Physical Chemistry Letters 2018, 9 (23), 6744-6749.

71. McDermott, M. L.; Vanselous, H.; Corcelli, S. A.; Petersen, P. B., DNA's Chiral Spine of Hydration. ACS Central Science 2017, 3 (7), 708-714.

72. Kocsis, I.; Sorci, M.; Vanselous, H.; Murail, S.; Sanders, S. E.; Licsandru, E.; Legrand, Y.-M.; van der Lee, A.; Baaden, M.; 
Petersen, P. B.; Belfort, G.; Barboiu, M., Oriented chiral water wires in artificial transmembrane channels. Science Advances 2018, 4 (3), eaao5603.

73. Wen, B.; Sun, C.; Zheng, W.; Bai, B.; Lichtfouse, E., Evidence for water ridges at oil-water interfaces: implications for ion transport. Soft Matter 2020, 16 (3), 826-832.

74. Qiao, B.; Littrell, K. C.; Ellis, R. J., Liquid worm-like and proto-micelles: water solubilization in amphiphile-oil solutions. Physical Chemistry Chemical Physics 2018, 20 (18), 12908-12915. 75. Thiyagarajan, P.; Diamond, H.; Danesi, P. R.; Horwitz, E. P., Small-angle neutron-scattering studies of cobalt(II) organophosphorus polymers in deuteriobenzene. Inorganic Chemistry 1987, 26 (25), 4209-4212.

76. Wang, H.; Yan, E. C. Y.; Borguet, E.; Eisenthal, K. B., Second harmonic generation from the surface of centrosymmetric particles in bulk solution. Chemical Physics Letters 1996, 259 (1), 15-20.

77. Zhao, X.; Subrahmanyan, S.; Eisenthal, K. B., Determination of $\mathrm{pKa}$ at the air/water interface by second harmonic generation. Chemical Physics Letters 1990, 171 (5), 558-562.

78. Zhao, X.; Ong, S.; Wang, H.; Eisenthal, K. B., New method for determination of surface $\mathrm{pKa}$ using second harmonic generation. Chemical Physics Letters 1993, 214 (2), 203-207.

79. Hankett, J. M.; Liu, Y.; Zhang, X.; Zhang, C.; Chen, Z., Molecular level studies of polymer behaviors at the water interface using sum frequency generation vibrational spectroscopy. Journal of Polymer Science Part B: Polymer Physics 2013, 51 (5), 311-328.
80. Zhang, C.; Chen, Z., Probing Molecular Structures of Poly(dimethylsiloxane) at Buried Interfaces in Situ. The Journal of Physical Chemistry C 2013, 117 (8), 3903-3914.

81. Jang, J. H.; Lydiatt, F.; Lindsay, R.; Baldelli, S., Quantitative Orientation Analysis by Sum Frequency Generation in the Presence of Near-Resonant Background Signal: Acetonitrile on Rutile TiO2 (110). The Journal of Physical Chemistry A 2013, 117 (29), 62886302.

82. Premadasa, U. I.; Adhikari, N. M.; Cimatu, K. L. A., Molecular Insights into the Role of Electronic Substituents on the Chemical Environment of the $-\mathrm{CH} 3$ and $>\mathrm{C}=\mathrm{O}$ Groups of Neat Liquid Monomers Using Sum Frequency Generation Spectroscopy. The Journal of Physical Chemistry C 2019, 123 (46), 28201-28209.

83. Chowdhury, A. U.; Liu, F.; Watson, B. R.; Ashkar, R.; Katsaras, J.; Patrick Collier, C.; Lutterman, D. A.; Ma, Y.-Z.; Calhoun, T. R.; Doughty, B., Flexible approach to vibrational sumfrequency generation using shaped near-infrared light. Opt. Lett. 2018, 43 (9), 2038-2041.

84. Chowdhury, A. U.; Watson, B. R.; Ma, Y.-Z.; Sacci, R. L.; Lutterman, D. A.; Calhoun, T. R.; Doughty, B., A new approach to vibrational sum frequency generation spectroscopy using near infrared pulse shaping. Review of Scientific Instruments 2019, 90 (3), 033106.

85. Ye, S.; Tong, Y.; Ge, A.; Qiao, L.; Davies, P. B., Interfacial Structure of Soft Matter Probed by SFG Spectroscopy. The Chemical Record 2014, 14 (5), 791-805. 
TOC Graphic

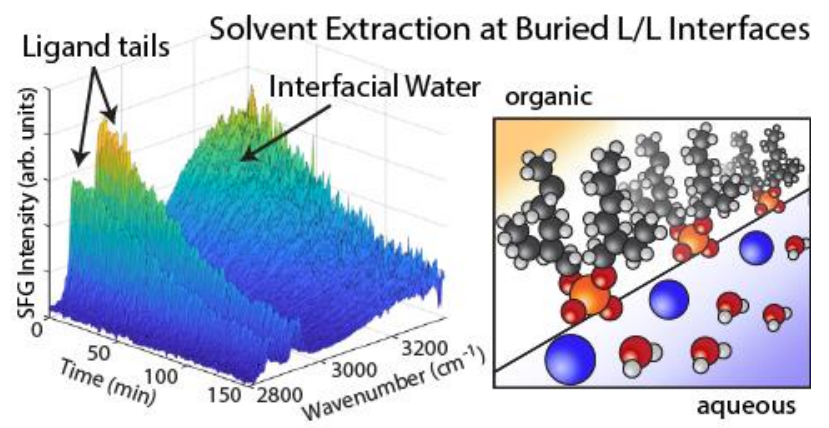

